\title{
Revisão narrativa sobre o novo modelo de financiamento da atenção primária em saúde no Sistema Único de Saúde - SUS
}

\begin{abstract}
Camila Medrado Alves CARNEIRO: Faculdade de Saúde Pública - FSP, Universidade de São
\end{abstract} Paulo - USP. ORCID: https://orcid.org/0000-0003-1109-6565

Áquilas MENDES: Faculdade de Saúde Pública - FSP, Universidade de São Paulo - USP. ORCID: https://orcid.org/0000-0002-5632-4333

\section{Resumo}

O financiamento da Atenção Primária à Saúde (APS) no Brasil vem sendo bastante discutido nos dois últimos anos. Isto porque foi alterado, por meio de decisão da recém-criada Secretaria de Atenção Primária à Saúde (SAPS) do Ministério da Saúde, tendo como responsável Erno Harzheim. Tal modificação foi introduzida pelo Programa 'Previne Brasil', criado pelo governo federal através da portaria 2.979, de 12 de novembro de 2019. Este programa estabelece um novo modelo de financiamento de custeio da Atenção Primária à Saúde no âmbito do Sistema Único de Saúde (SUS) tendo como base: I) captação ponderada, II) pagamento por desempenho e III) incentivo de ações estratégicas. Essa alteração no modelo de financiamento pressupõe equilíbrio entre custos, ampliação de acesso, qualidade e quantidade de serviços ofertados e avaliação dos resultados. Contudo, várias críticas vêm sendo feitas a esse modelo pelas entidades associadas ao Movimento da Reforma Sanitária. Dentre elas, ressalta-se o fato de que a modificação do financiamento da APS rompe com o Piso da Atenção Básica (PAB) fixo, implantado desde 1998, em que assegurava um valor per capita total repassado para o município, a fim de que ele pudesse planejar e executar as ações e serviços de saúde nesse nível de atenção como um todo, respeitando os princípios constitucionais do SUS. Além disso, comenta-se que do ponto de vista da equidade o novo modelo não segue as determinações dispostas pela Lei $n$. 141/2012, artigo 17 em que o critério guia para transferência dos recursos federais aos municípios refere-se às necessidades de saúde. Entende-se que o modelo de atenção deve

Recebid o: 5 out. 2020 Aceito: 21 out. 2020

Autor de correspondência: Camila Medrado Alves Carneiro

camila.medrado@yahoo.com.br

Conflito de interesses:

Os autores declaram não haver nenhum interesse profissional ou pessoal que possa gerar conflito de interesses em relação a este manuscrito. ser o orientador do processo de financiamento e, sendo a APS a porta de entrada e ordenadora da atenção à saúde do SUS, deve dispor de um financiamento compatível à sua abrangência. A APS tem se mostrado cada vez mais importante, dispondo de rede de serviços multidisciplinares e autonomia para resolver até $85 \%$ dos problemas de saúde, sem a necessidade de tecnologias mais densas. Mas, mesmo utilizando tecnologias mais leves, isso não faz desse nível de atenção menos dispendioso. Esses são alguns dos motivos pelos quais a APS vem sendo muito estudada, em especial em seu modo de financiamento, tendo como objetivo a sua melhoria contínua para o enfrentamento dos desafios de ordem estruturante. A proposta do novo modelo de financiamento foi elaborada a partir de estudos com exemplos internacionais, observando resultados de países que também tem a APS como base, teve apoio do CONASS, CONASEMS e do Banco central. Entretanto há questionamentos quanto aos efeitos da mudança no modelo de financiamento apresentando pela SAPS, pois mesmo fundamentado em estudos internacionais, faz-se necessário avaliar suas reais limitações e perspectivas, tendo em vista que o cenário socioeconômico do Brasil é diferente de outros países que também utilizam sistemas universais de saúde. Desta forma, o presente estudo pretende analisar os limites e as perspectivas do novo modelo de financiamento na APS. Objetivo: Apresentar uma análise a respeito do novo modelo de financiamento da atenção primária em saúde tendo como 
base a literatura científica disponibilizada pelo seu mentor Erno Harzheim, Secretário da Atenção Primária do Ministério da Saúde (2019-2020). Como objetivos específicos, este estudo visa: a) Sistematizar os artigos, na literatura científica nacional sobre o novo modelo de financiamento da atenção primária em saúde no SUS, de autoria de Erno Harzheim; b) Analisar os principais temas relacionados, identificados nos artigos científicos, buscando compreender a abrangência do novo modelo de financiamento da atenção primária em saúde no SUS; c) Discutir o novo modelo de financiamento da atenção primária em saúde no SUS em relação aos motivos que o criaram, seus avanços e limites em relação à melhoria desse nível de atenção à saúde. Método: $O$ estudo trata-se de uma revisão narrativa, tendo como pergunta de pesquisa: o que a literatura científica disponibiliza sobre o novo modelo de financiamento da atenção primária em saúde no SUS à luz da contribuição de Erno Harzheim, destacando limites e perspectivas no âmbito da gestão?. Optou-se por trabalhar com o Google Acadêmico para a busca de artigos de Erno Harzheim, à medida que se trata de uma forma simples e direta de pesquisar literatura acadêmica. A busca se limitou aos artigos desse autor publicados a partir do ano 2019. Em 13 de agosto de 2020, foram feitas pesquisas no Google Acadêmico, inserindo no campo de pesquisa o nome de Erno Harzheim, estabelecendo o filtro para artigos desde 2019. Considerações finais: Após esse processo de busca obtivemos o resultado de 77 artigos, que foram extraídos e passaram por um processo de seleção, a fim de obter somente artigos relacionados ao assunto relacionado à pergunta de pesquisa. Foram excluídos 41 artigos no idioma inglês, 21 artigos que não eram de autoria do Erno Harzheim, 1 monografia e 5 artigos que não estavam relacionados ao assunto. Dessa forma, restaram 9 artigos incluídos para a revisão.

Descritores: Financiamento da Assistência à Saúde; Atenção Primária à Saúde; Sistema Único de Saúde.

Keywords: Healthcare Financing; Primary Health Care; Unified Health System.

Palabras-claves: Financiación de la Atención de la Salud; Atención Primaria de Salud; Sistema Único de Salud. 